\section{¿QUÉ DEBE HACER EL GOBIERNO LOCAL ANTE LOS GRANDES EMPRENDIMIENTOS EN EL COMERCIO MINORISTA?}

\author{
José Luis Coraggio \\ RUBEN CESAR
}

\begin{abstract}
R E S U M E N A raiz de la situación planteada por la solicitud de la empresa Carrefour de instalar un segundo supermercado en la ciudad de Porto Alegre, se suscitó una polémica a la cual este artículo pretende aportar datos de la experiencia argentina de penetración de ese tipo de megaemprendimientos comerciales. A la vez se plantean algunas vías de acción alternativa, tanto en lo referente a la negociación con el gran capital foráneo como en lo referido al fortalecimiento de opciones más competitivas para el pequeño comercio local.
\end{abstract}

\section{PALABRAS-CLAVE Emprendimientos comerciales; capital comercial; impacto económico; alianza popular.}

\section{LA CUESTIÓN PLANTEADA}

La pregunta se planteó a partir de la decisión de la cadena Carrefour de poner en marcha la instalación de un segundo hipermercado en la ciudad de Porto Alegre, solicitando a la Prefectura el estudio de la viabilidad urbanística del dicho proyecto. El anterior hipermercado data de hace quince años, y está ubicado en la zona sur de la ciudad, en una ubicación a la que acceden fundamentalmente sectores de clase media baja y baja. En cambio, el segundo estaría en una zona de mayor densidad y afluencia económica, a pocos metros de otros supermercados y shoppings propiedad de capitales de Rio Grande do Sul. Es interesante tener en cuenta que Carrefour ya tiene adquirido ese terreno y otro más, en otro punto estratégico de la ciudad. La discusión aparece centrada en el impacto económico concentrador de tal inversión sobre la estructura económica de la ciudad y en particular sobre el sector comercial de porte mediano y pequeño, con su consecuente repercusión sobre el tejido social.

Esto ha abierto una polémica sobre el papel del gobierno local, en el contexto de un proyecto político democrático participativo, que debe atender a un amplio espectro de intereses locales. ${ }^{2}$ De alguna manera esta contradicción entre fracciones del capital (extranjero/nacional) incita a replantear en el seno de las fuerzas políticas de izquierda la vieja cuestión de si hay que diferenciar políticamente entre una y otra fracción del capital o si hay que darles el mismo tratamiento. Esto se manifiesta de algún modo en la posibilidad de introducir una disposición que limite futuras localizaciones o bien una que intente regular a todos los emprendimientos de gran porte, anteriores o futuros. Al respecto, circuló un proyecto que intenta suspender toda decisión sobre megaemprendimientos

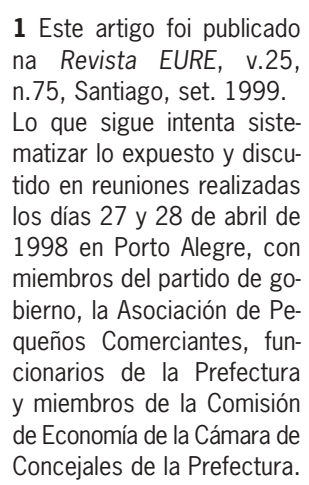

Concejales de la Prefectura.

2 La discusión está aparentemente alimentada por la necesidad de atender a los intereses de capitales comerciales concentrados de origen regional, de los propietarios de pequeños comercios y de los trabajadores mercantiles, y a la vez sostener la visión utópica de ciudad generada a partir del encuentro Ciudad Constituyente. 
comerciales (mayores de $3.500 \mathrm{~m}^{2}$ ) hasta que fueran establecidos nuevos parámetros en el nuevo Plan Director de la ciudad.

Al encarar la cuestión, habría que intentar ubicar este episodio dentro del marco prospectivo más general que impone el proceso de reestructuración tecno-productiva del capital a escala global y las políticas de ajuste neoliberal. Esto es conveniente para definir el campo de acción pública efectiva posible tanto como para anticipar las consecuencias de cada respuesta política alternativa (negociación o rechazo, regulación o desregulación total, referencia exclusiva a inversiones de origen extranjero o a todo megaemprendimiento comercial, etc.) dentro del movimiento general de redefinición de las relaciones entre sociedad, economía y estado. Para avanzar en esa dirección es que puede ayudar comparar con la experiencia argentina, donde se inició antes la apertura neoliberal. A la vez, el hecho de que en Porto Alegre se esté recién entrando en un proceso de introducción masiva del gran capital comercial, con un contexto político local excepcional para América Latina, permite pensar alternativas innovadoras ante la cuestión general.

\section{EL CONTEXTO GENERAL}

El gran capital comercial invade América Latina ¿Por qué ahora? Se dice que el comercio internacional se concentra en el intercambio entre los países más desarrollados, entre los sectores de mayores ingresos, entre los nuevos ricos y las nuevas clases medias. $\mathrm{Si}$ nuestras economías tienen un peso decreciente en el mercado global, con mercados internos polarizados entre un pequeño sector de alto consumo sofisticado y masas crecientes de sectores excluidos de consumos no esenciales, con sectores medios en proceso de empobrecimiento, ¿cuál es el interés del capital comercial internacional en realizar cuantiosas inversiones en la región en este momento?

En primer lugar, las limitaciones históricas al avance de los monopolios de la comercialización minorista en los Estados Unidos (donde las cinco mayores redes controlan apenas el 32,6\% contra el 70\% en Francia y el 60\% en Argentina, en parte por las leyes antimonopólicas, en parte por la resistencia de comunidades locales a la entrada de los hipermercados), en segundo lugar la saturación del mercado europeo y las nuevas leyes en Francia (la Ley Galland prohibió la instalación de comercios mayores de $300 \mathrm{~m}^{2}$, equivalentes a un autoservicio de barrio $)^{3}$ han precipitado a los conglomerados de la comercialización minorista a invertir en Asia y Latinoamérica.

Además, la reciente crisis asiática posiblemente aumentará la atracción relativa del mercado latinoamericano: un continente con un mercado territorialmente concentrado por el elevado grado de urbanización, con ingresos per capita urbanos que - a pesar de la degradación sufrida en estas dos décadas - se destacan fuera de los países de la OECD, con una cultura popular marcada por las propuestas mediáticas consumistas y modernizantes, que ve la llegada de cada nuevo emprendimiento gigante e innovador como símbolo de progreso, con monedas ahora estables, con facilidad para importar bienes y remitir ganancias a los países de origen bajo el férreo control del FMI y el BM.

A esto se agregan las nuevas oportunidades de innovación que abre la revolución tecnológica (comunicaciones, informatización, transportes) y organizativa (descentralización del control, just in time), las que requieren inversiones masivas para su completa efectivización. Y esto incluye los mercados crecientemente uniformizados de bienes de primera necesidad, de bajo precio pero volúmenes enormes a escala global. Todo esto explica por 
qué los monopolios continúan su competencia ahora en el mercado periférico global y despliegan en América Latina estrategias globales para captar los mercados urbanos locales.

La decisión de Carrefour que detona la cuestión en Porto Alegre forma parte entonces de un proceso de extensión y generalización de los monopolios en la esfera de la comercialización y de una nueva profundización de la cultura consumista, y desde allí su penetración de nuevos estilos de articulación entre servicios, producción y consumo en la esfera de la producción de productos de consumo masivo.

Las modalidades de interacción de estos emprendimientos en el mercado pueden ser caracterizadas como oligopolio (pocas grandes empresas controlan un alto porcentaje del mercado, fijando las condiciones paramétricas para las acciones de un resto del mercado fragmentado y orientado hacia "nichos" o intersticios del mercado local) con prácticas de competencia monopólica (fusiones, guerra o acuerdo de precios, diferenciación de productos, etc.). Mientras las modalidades de penetración del mercado de los primeros conglomerados pueden ser vistas como dirigidas a anular la competencia de los comercios tradicionales, una vez instalados en un mismo mercado local varios competidores del mismo porte, tales políticas pasan a estar dominadas por la competencia entre los grandes, con los pequeños comercios sufriendo las consecuencias de políticas no dirigidas necesariamente a ellos.

Se trata en todos los casos de inversiones de cientos de millones de dólares, asociadas a grandes capitales, nacionales o no. A través de la compra de cadenas preexistentes producen fusiones y absorciones horizontales para reducir la competencia. ${ }^{4}$ En Brasil: la compra de la red baiana Supermar en 65 millones de dólares por Bompreço (tercero en el ranking de facturación), socio del grupo holandés Royal Ahold, y con una inversión prevista de 170 millones para expandir y equipar la red; la compra por Carrefour de Eldorado, la oferta de Pão de Azúcar (segundo en el ranking, que ya ha adquirido seis redes menores en el 1997) de comprar la red G. Aronson; la disposición del Banco Pontual al abrir una cartera de 350 millones para invertir en la participación de empresas de este porte, ${ }^{5}$ y las negociaciones en marcha de los grandes para absorber tres empresas con facturación entre 250 y 500 millones anuales (Cândia y Barateiro de São Paulo, ABC de Río de Janeiro). En Argentina: ${ }^{6}$ la compra por Disco (con más de 100 bocas de expendio, ahora asociada con los capitales holandeses de Royal Ahold) de la cadena Su Supermercado por 75 millones en el Oeste del Gran Buenos Aires, de Santa Isabel (Chilena), de Vea (en Mendoza y Córdoba), de las cadenas Elefante, La Gran Provisión y Frigosol; Coto compró la cadena Acassuso y Metro (local en Buenos Aires); Norte (desde el 1996 adquirido en 440 millones de dólares por el Exxel Group de Estados Unidos, que también compro dos cadenas chicas del Norte del GBA (La Florida del Norte y Tanti) compró el hipermercado Tigre (de $18.000 \mathrm{~m}^{2}$ en Rosario); Wal Mart intentó comprar Jumbo (de la cadena Chilena Cencosud); Auchan entró comprando los siete hipermercados del grupo Libertad (en Córdoba, Tucumán, Santiago del Estero y Resistencia). Si la Argentina contara con leyes antimonopolio como las de Estados Unidos, una parte de las transacciones mencionadas deberían haber sido examinadas por su potencial anticompetitivo, pero en un sistema sin regulación la furia fusionista sigue desatada.

\section{LA SITUACIÓN EN ARGENTINA}

Esta dinámica vertiginosa se expresa asimismo en la inversión en marcha para la ampliación de los locales adquiridos o la construcción de nuevos hipermercados o centros

4 Los cinco mayores grupos en Brasil (Carrefour, Pão de Azúcar, Bompreço, Sendas y Paes Mendonça, en ese orden, cubren el $28 \%$ de un mercado estimado en 50 mil millones de dólares anuales); Folha de S. Paulo, $2^{\circ}$ Caderno, p.1, 13 de abril de 1998. Los ocho grandes grupos en Argentina (Carrefour, Disco-Royal Ahold, Coto (Nacional), Norte-Exxel, Tía (Nacional), Jumbo-Sencosud, Wall Mart y ahora Auchan-Casino) tienen un volumen de facturación que sobrepasa los 10 mil millones de dólares. El $71 \%$ de las ventas de alimentos $y$ bebidas en todo el país pasaban en 1996 por HIPER, SUPER Y AUTOSERVICIOS, y en el Area Metropolitana aumentaba al 80,7\%. Pero mientras los hiper y super mercados (4 o más cajas) cubrían con 1.200 locales el $47 \%$ del rubro alimentos y bebidas, los autoservicios de hasta tres cajas cubrían con 12.500 locales el $25 \%$ y los almacenes tradicionales el $28 \%$ con 114.000 locales en el país; Clarín, Suplemento de Economía, p.22, 5 de octubre de 1997. En abril de 1997 el Indec registraba 11 cadenas grandes $y$ 51 medianas en el país. Mientras las grandes facturaban el $93 \%$ y las medianas el $7 \%$ del conjunto, las primeras estaban creciendo y las segundas reduciendo su peso. El valor de cada venta promedio de las primeras era de $28 \$$, el de las segundas era $15 \$$. En las cadenas medianas el $79 \%$ de las ventas son alimentos y bebidas, en las grandes sólo el 66\%. En electrodomésticos y artículos para el hogar es respectivamente de $0,5 \%$ y de $5 \%$. La facturación en 1997 de algunos de los grandes estaba estimada como sigue: Carrefour (2.400 millones), Disco (1.600), Coto (1.300), Norte (1.300), Tía (700), Jumbo (550).

5 Folha de S. Paulo, $2^{\circ}$ Caderno, p.1, 13 de abril de 1998.

6 Clarín, Suplemento de Economía, p.22, 5 de octubre de 1997. 
7 Clarín, p.26, 11 de diciembre de 1997.

8 La legislación prohibe a las autoridades comunales modificar las zonificaciones previstas para cada radicación en la provincia. También quedan inhabilitadas las ordenanzas para la exención de tributos a favor de los hipermercados. (Clarín, p.30, 20 de marzo de 1998 .

9 Clarín, 23 de noviembre de 1998.

10 Clarín, p.26, 11 de diciembre de 1997.

\section{¿ Q U É $\mathrm{D}$ E}

comerciales en las grandes ciudades o en centros intermedios de la red urbana. Algunos ejemplos: Wal Mart en La Plata, Bahía Blanca, Santa Fe, Paraná, Neuquen, y Córdoba (dos supercenters con un total de $36.000 \mathrm{~m}^{2}$ y 40 millones de dólares), Jumbo en Córdoba, Martínez, San Isidro y Neuquen, que además abrió un shopping de 42 millones de dólares en Quilmes, complementario del Hiper y el Easy Home en esa zona; Carrefour en el ex albergue Warnes y varios locales en Córdoba; Coto en Lanús (un hiper con shopping de más de 30 millones de dólares), Temperley y El Abasto, Mataderos y Barrio Norte; Tía en Corrientes $\left(11.000 \mathrm{~m}^{2}\right)$, Usuhaia, Comodoro Rivadavia, Trelew y General Roca además de otros dos en la Capital Federal; Disco en Capital y Córdoba; Norte en Lomas de Zamora, en las provincias de San Luis, Santa Fe y Entre Ríos (para 1998 preveían un local nuevo por mes); a todo lo cual viene a sumarse Auchan (del grupo Casino, competidor francés de Carrefour) que abrió su primer hipermercado en Avellaneda y está planificando un segundo en la periferia de la Capital. ${ }^{7}$

Con inversiones mínimas de 10 millones pero que pueden llegar a 140 millones (Warnes) se vienen abriendo hiper y super mercados en los grandes centros y ahora en la periferia a razón de más de uno por mes. Estos gigantes pueden adaptarse, y atender no sólo los grandes mercados concentrados sino localidades como Neuquen. En esta competencia pueden asociarse con grupos financieros e inmobiliarios para avanzar combinando supermercados, edificios de vivienda u oficinas y shoppings. A esta altura, la reciente ley de la Provincia de Buenos Aires ${ }^{8}$ exigiendo la realización de estudios previos a la aprobación de inversiones adicionales que superaran los $2.500 \mathrm{~m}^{2}$ no puede sino ser vista como tardía, y hasta ha sido juzgada como atentatoria de la competencia al limitar la presión de futuras entradas en el mercado ya copado por los megaemprendimientos existentes.

Si bien tienden a especializarse en diversos segmentos del mercado: de nivel alto (Norte), medio (Disco), y popular (Wal Mart, Carrefour, Coto), y no cubren siempre las mismas líneas de productos, es evidente que estos conglomerados comerciales están empeñados en una lucha por nuestros mercados urbanos, lo que se expresa en la multiplicación de bocas de salida para cubrir el territorio. Si bien se considera viable un hiper cada 200 a 250 mil habitantes, esta multiplicación de bocas es resultado no de acuerdos o de la programación óptima concertada del sector para minimizar costos de abastecimiento a la población (o para maximizar las ganancias del conjunto de las empresas), sino de una fase de fuerte competencia entre los monopolios.

Esta competencia territorial, requiere ubicarse en las mejores posiciones centrales del mercado urbano, comprando establecimientos existentes en zonas de concentración histórica del mercado o anticipándose a comprar los grandes terrenos vacantes aún disponibles. Iniciada en los grandes mercados de las áreas metropolitanas, donde ganaban varias veces más que en sus mercados de origen - por la combinación de falta de competencia inicial, menores costos de mano de obra, suelo, impuestos (apenas el $4 \%$ del valor de ventas en RA etc.) - , de ahí se extendieron a otros centros de la red urbana y a barrios periféricos de menor ingreso y comienzan a interceptar agresivamente sus áreas de venta.

Esta lucha hace que venga bajando el rendimiento por $\mathrm{m}^{2}$ (desde 1994 la facturación por $\mathrm{m}^{2}$ de cuatro de las grandes cadenas de super cayó un 35\%, y en septiembre de 1998 cayó un 13\%; ${ }^{9}$ sin embargo, los 885 dólares promedio en 1997 siguen siendo superiores a los 350 por $\mathrm{m}^{2}$ en Brasil y dos veces la media de Chile, de $\left.453 \$ / \mathrm{m}^{2}\right)^{10} \mathrm{y}$ que aunque se sigan agregando lugares de expendio la proporción del mercado que controlan las grandes cadenas comienza a estabilizarse (las ventas globales no aumentan ya 
en una proporción equivalente al incremento en el número de locales). Puede ser que como resultado de esta lucha no todas las grandes cadenas permanezcan en el futuro, pero en todo caso es de prever que esta furia de inversión y fusiones se vaya frenando con los límites del mercado. En todo caso, su competencia monopólica no es ya principalmente contra el mercado microminorista, sino entre ellas, aunque golpean al micro como consecuencia de sus avances.

Por su misma magnitud, esta lucha se va manifestando en la reestructuración del espacio urbano, contribuyendo, junto con la proliferación de shoppings y barrios cerrados, a extender una cultura de compra y consumo en espacios quasi públicos que ofrecen la posibilidad de realizar compras y consumo de productos y servicios muy diversos con un solo traslado. Esto se refuerza con la creciente presencia en el imaginario y en la vida cotidiana real de la inseguridad y creciente violencia en las calles, algo que de hecho afecta directamente la competitividad de los pequeños comercios, asaltados con frecuencia inusitada en los últimos años.

Pero la lucha no se limita a la fusión y extensión de grandes locales. Así, utilizan nuevas tecnologías de comercialización que descolocan al comercio tradicional: asociados con el capital financiero, emiten sus propias tarjetas de crédito de fácil acceso (a mediano plazo, dando acceso a bienes de consumo, pero con tasas de interés usurarias), a pesar de su escala cuando se dirigen a sectores medios y altos ofrecen servicio a domicilio, utilizan ofertas gancho bajando los precios de algunos productos por debajo del costo, realizan sorteos entre los compradores presentes, etc.

La lucha por controlar una proporción más alta del mercado de consumo es también instrumental para ejercer un poder monopólico en el mercado de productos, donde se presentan como grandes compradores: el ejercicio de ese poder incide en los precios que reciben los proveedores (hasta un 20\% de menor precio por el producto además del pago de un derecho fijo para exponer en las góndolas y el usual pago por metro lineal de góndola), así como la imposición de plazos de pago (a 60 o 90 días). La escala les permite también convertirse en importadores y exportadores (de productos de su propia marca) y acceder a tecnologías de punta (cajas conectadas con sistemas informatizados de inventario y control de la salida por producto, posición en las góndolas, cruzando casi instantáneamente el análisis de la demanda con la información sobre los compradores con tarjeta, etc.).

La escala también les permite hacer producir a façon productos con su propia marca (el 8\% de lo que facturan los grandes; ${ }^{11}$ mientras en Francia, Carrefour tiene 1.600 productos de línea propia que son el 16\% de sus ventas, en Argentina esperan tener 400 productos con marca propia para el 2000). Al evitar costos de distribución y de marketing logran por este medio bajar los precios un promedio de $15 \%$ por debajo del precio de lista en las marcas líderes; algunos productos pueden ser exportados a sus locales en otros países - duraznos, hamburguesas, etc. ${ }^{12}$ En esto hay diferencias: Norte, dirigido a un mercado de mayor nivel de ingresos, trabaja con las marcas conocidas, mientras que Carrefour y Disco generan sus propias marcas.

Estos emprendimientos comerciales no sólo ejercen el comercio minorista en gran escala, sino que compiten con el comercio mayorista (muchos comercios pequeños se abastecen en los super o hiper). También usan formas de competencia desleal e ilegal: pueden vender productos por debajo del costo, eludir aduanas (recordemos los juicios pendientes por utilizar la "aduana paralela", pasando containers que no pagaban impuestos porque supuestamente estaban en tránsito hacia otro país), anunciar rebajas en diarios y en las góndolas y no registrarlos en las cajas, etc.
11 Suplemento Cash, p.12, 11 de diciembre de 1997.

12 El Cronista, p.10, 21 de mayo de 1997. 
13 Más aún, el 62,7\% opina que la situación empeorará y el $29,5 \%$, que se mantendrá igual.

14 Clarín, p.20, 23 de febrero de 1998.

15 Clarín, p.24, 18 de Mayo de 1998.

16 Clarín, p.20, 23 de febrero de 1998.

17 Suplemento Cash, p.12, 15 de diciembre de 1997.

\section{; Q U E E}

\section{EL IMPACTO}

El impacto urbano de esta reorganización del comercio no es menor: el comercio tradicional, pequeño e incluso bajo la forma de cadenas especializadas, sufre la quiebra de los comercios peor colocados - por su localización o su ineficiencia —, con la consiguiente pérdida de empleos y en ocasiones la desvalorización de sus propiedades en zonas que constituían centros comerciales de la ciudad. Esto a su vez afecta indirectamente a las redes de abastecimiento de esos comercios, muchas de cuyas PYMES no pueden cumplir con los requerimientos de las grandes cadenas en lo referente a calidad, precio, cantidad y continuidad dentro de un régimen "just in time".

Es importante señalar que el $83 \%$ de los comerciantes pequeños reconoce que la instalación de hipermercados tiene un efecto negativo sobre sus comercios. ${ }^{13}$ Esto no surge de una interpretación subjetiva de estos comerciantes, sino que está basada en datos de la realidad de estos comercios, que ven como sus ventas se reducen mientras que la participación de los hipermercados en el mercado minorista aumenta. Por ejemplo, basado en datos del Indec, la facturación de los hipermercados aumentó en abril de 1997 un 9,6\% con respecto a igual período del año anterior y el 92,9\% del total de la facturación de abril de 1997 correspondía a las grandes cadenas de supermercados, restando el 7,1\% para las medianas, ${ }^{14}$ en abril de este año las grandes cadenas facturaron un $11,8 \%$ más que en igual período del año anterior mientras que los comercios chicos perdieron un $0,2 \%$ en el mismo período. ${ }^{15}$ La tendencia al aumento de la facturación por parte de los hipermercados continua en 1998, dado que, desde septiembre de 1997 hasta el mismo mes de 1998, el monto total de las ventas de éstos aumentó un 10,5\%.

En el interior del país la imagen es similar, la entrada de los hipermercados en estos mercados redujo la participación de las ventas de los comercios pequeños de un $22 \%$ en 1996 a un $16 \%$ en $1997,{ }^{16}$ mientras los hipermercados siguen abriendo comercios en la zona.

Tiene también un impacto sobre la recaudación impositiva local, provincial y nacional. En esto incidirán los sistemas impositivos regresivos, en el sentido de que las tasas que pagan los pequeños comerciantes son iguales que las de los grandes, el efecto de la negociación de tasas especiales y la capacidad de evasión. Por lo pronto, la competencia ruinosa a la que están sometidos entre estos gigantes y el comercio ambulante, empuja a los pequeños y medianos comercios a bajar costos evadiendo impuestos. En cuanto al efecto sobre el balance de pagos nacional, es sin duda negativo: por su tendencia a importar directa y masivamente productos de bajo costo para sustituir la oferta nacional, y por su tendencia a remitir ganancias al exterior.

Su efecto sobre el espacio público y la organización de la ciudad no será el mismo para cada caso y localización, pero en conjunto contribuye significativamente a cambiar el paisaje urbano y los modos de circulación y convivencia en la ciudad. La revalorización del suelo y las propiedades inmobiliarias en ciertas zonas puede inducir nuevas densificaciones. Puede hacer perder centralidad al viejo centro si se concentran en ubicaciones periurbanas, pero si se ubica en lugares cercanos puede revalorizarlo. Concentra efectos ambientales negativos en su entorno (contaminación del aire y sonora, problemas de drenaje, embotellamientos de tránsito, etc.), algunos de los cuales pueden ser compensados con obras especiales, otros no.

En cuanto al impacto sobre los precios al consumidor, es en promedio positivo: pueden llegar a estar un $20 \%$ por debajo de sus competidores tradicionales ${ }^{17}$ y un $10 \%$ 
por debajo de los autoservicios (menos de cuatro cajas registradoras). Aunque se especula con la posibilidad de que una vez establecidos suban los precios, mientras persista la actual fase de competencia monopólica será difícil un acuerdo para subir los precios. Pero no todos los consumidores pueden prescindir del pequeño comercio, y en este sentido es importante marcar que el mercado que queda para estos es el de la gente que recurre para comprar los productos de primera necesidad ${ }^{18} \mathrm{o}$ los que no pueden acceder al tipo de compra concentrada e impersonal que propone un hipermercado. Mucha gente, a pesar de que en el mediano plazo termina pagando más caro en un almacén que en un hipermercado, en los almacenes puede desarrollar estrategias de compra que sería imposible desarrollarlas en estos grandes emprendimientos, por ejemplo el retiro de mercaderías con pago diferido, más conocido como "fiado de mercadería" o la compra de pequeñas fracciones de peso para atender la necesidad del momento. ${ }^{19}$ En lo que hace a los salarios y los derechos laborales, su carácter de pertenecientes al sector "formal" no impide que utilicen las formas de trabajo precario que permite la práctica de contratación en un mercado con altas tasas de desempleo y desregulación creciente.

Combinando todos estos factores, su condición monopólica les permite obtener tasas de ganancia hasta cuatro veces superiores a las logradas en sus países de origen. Sin embargo, el efecto económico es contradictorio: por un lado (al menos mientras subsista la competencia) se bajan los precios de los productos de consumo y se aumentan los ingresos de aquellos comerciantes que pueden beneficiarse por estar asociados a estos centros (aunque se dan muchos casos de quiebra posterior por no poder afrontar los altos costos de participar del espacio en los centros comerciales), por otro se reducen los ingresos de los trabajadores y de los propietarios que pierden en la competencia o que no se benefician con esa asociación. En todo caso, las ganancias del sector comercial, crecientemente monopólicas, serán socializadas de otra manera (se filtran hacia procesos globales de inversión).

En todo esto hay que tener en cuenta que el impacto económico no puede ser evaluado simplemente asignando a los nuevos emprendimientos comerciales la responsabilidad por los índices de quiebras o desempleo del comercio minorista. Se están produciendo otros fenómenos que forman parte de un proceso de reestructuración profunda del sector comercial y de servicios en general. En primer lugar, en parte son consecuencia de los violentos procesos de redistribución del ingreso provocados por el estilo de ajuste estructural impuesto. Por otro lado, están entrando con fuerza las modalidades de CADENAS DE DISCOUNT (Tía, francesa), que en locales chicos venden artículos de marca propia, un $20 \%$ más baratos,$^{20}$ los que compiten con tiendas o cadenas de electrodomésticos locales. Se desarrollan cadenas especializadas de venta de electrodomésticos, equipos de sonido, computación, grabaciones musicales, etc. Los comercios de alimentos, artículos de limpieza y tocador son los más afectados y sin respuesta por la invasión de los supermercados. Noventa y seis mil almacenes han sido transformados en autoservicios en 5 años, y otros 100 mil están previstos en los próximos dos años. ${ }^{21}$ Aparecieron los Convenience Stores (asociados a gasolineras, ubicadas centralmente respecto al mercado de automovilistas). Las cadenas especializadas comercializan grandes volúmenes con bajos márgenes y pobre presentación y servicio en locales autoservidos de $200 \mathrm{~m}^{2}$. Entran con mejores condiciones de crédito en mercados superexplotados por tasas usurarias.

Por supuesto, hay otras formas de competencia representada por los shoppings o centros comerciales (en 1997, 35 shoppings facturaban 4.000 millones de dólares al año y recibían 130 millones de personas), ${ }^{22}$ que compiten fuerte en el rubro vestimentas,
18 Clarín, Suplemento de Economía, p.12, 5 de octubre de 1997.

19 Esto queda revelado cuando comparamos las frecuencias de asistencia a estos comercios, que se distribuyen en: todos los días al almacén y cada veinte días al hipermercado. (Algún diario.)

20 Clarín, p.46, 27 de octubre de 1997.

21 Clarín, p.12, 5 de octubre de 1997.

22 Clarín, p.22, 5 de octubre de 1992. 
23 Clarín, p.20, 23 de febrero de 1998.
24 La Capital, Rosario, 14 de febrero de 1998.

25 El Diario, Paraná, 18 de Febrero de 1998.

26 Ámbito Financiero, 27 de febrero de 1998.

27 La Voz del Interior, Cór doba, 12 de marzo de 1998

28 Buenos Aires Económico, 12 de marzo de 1998.

29 La Nación, 9 de marzo de 1998.

30 La Gaceta, Tucumán, 22 de febrero de 1998.

31 El Argentino, Gualeguychú, 2 de marzo de 1998.

32 La Razón, 22 de Febrero de 1998.

33 El Economista, 27 de febrero de 1998.

34 Revista Mercado, marzo de 1998.

35 Buenos Aires Económico, 12 de marzo de 1998.

36 El Comercial, Formosa, 25 de marzo de 1998.

¿ Q U É D E B E

juguetería, librería, electrodomésticos, computación, discos, centros de diversión, comidas, etc., y ahora comienzan a incluir hoteles. Sólo en el rubro ARTEFACTOS DEL HOGAR, con una facturación de 2.500 millones en 1997 entre hiper, super y cadenas especializadas en artefactos para el hogar, en menos de 3 años desaparecieron 2 mil comercios minoristas en ese rubro (incluidas cadenas nacionales o locales tradicionales). ${ }^{23}$ Actualmente buscan expandirse en los mercados periféricos de las metrópolis o del interior donde los hogares tienen necesidades de equipamiento altamente insatisfechas.

\section{TENDENCIA AL AVANCE A TRAVÉS DE LA RED URBANA}

En Rosario, Coto adquirió los terrenos de la Yerbatera Martin, Jumbo los terrenos de la ex textil Estexa y el grupo Casino el 30\% de la cadena Libertad. ${ }^{24}$ En Paraná Wal Mart abrió en febrero de este año un local de $13.500 \mathrm{~m}^{2}$ cubiertos, ${ }^{25}$ la misma empresa está construyendo otro hipermercado en Neuquen que abriría sus puertas en junio de este año ${ }^{26}$ también en Córdoba abrió un local de $17.000 \mathrm{~m}^{2}$ que requirió una inversión de 20 millones de pesos y tiene previsto abrir otro en el mes de junio de este año, ${ }^{27}$ la empresa planea abrir 36 hipermercados más en este año ${ }^{28}$ concentrándose fundamentalmente en el interior del país, más precisamente en las ciudades de Rosario y Tucumán. ${ }^{29}$ Norte tiene pensado abrir 11 nuevos locales durante $1998,^{30}$ en este año inició sus actividades en Concordia, en breve comenzará a instalarse en Gualeguaychú y compro la cadena Abud de Paraná. ${ }^{31}$ Carrefour en Adrogué (provincia de Buenos Aires) inauguró su hipermercado número 19 con una inversión de 30 millones de pesos. ${ }^{32}$ Disco está en plena etapa de expansión, el año pasado compró la cadena Vea que tiene 26 locales repartidos entre Mendoza y San Juan y uno en Córdoba. ${ }^{33}$ La principal cadena de descuento Tía decidió instalar en Argentina 400 sucursales durante este año, bajo la consigna "el precio de Carrefour a la vuelta de su casa". ${ }^{34}$ Auchan tiene pensado abrir su segundo hipermercado para el segundo semestre de este año en el barrio de Saavedra en Buenos Aires. ${ }^{35}$

Según datos de la consultora A. C. Nielsen en 1997 en el GBA los super, hiper, y autoservicios canalizan el 53,5\% de las ventas alimentarias y en el interior concentran el $44 \%$ de las ventas, estas cifras tienden a acrecentarse por el avance de los hipermercados en el interior: en Mendoza captan el 90\% de las ventas, en Tucumán, Córdoba, Mar del Plata y Bahía Blanca superan el 80\%. ${ }^{36}$

\section{CÓMO RECIBE EL MERCADO LOCAL ESTAS GRANDES INVERSIONES}

Tras repasar la información de medios de comunicación locales se advierte que hay dos posturas básicas ante las cuales los gobiernos de las ciudades del interior deben arbitrar de forma equitativa: por un lado, los intereses de los consumidores, ya analizados anteriormente. Por otro lado, los intereses de los productores y los comerciantes locales, que se ven amenazados por su incapacidad para competir en las mismas condiciones con los hipermercados.

Los comerciantes locales y sus empleados se ven amenazados por que no pueden igualar las ofertas de los hipermercados y su clientela tiende a reducirse a tal punto que 
ya no pueden mantenerse como oferentes en el mercado. Los productores, los comerciantes mayoristas y sus empleados también se ven amenazados, ya que el cierre de los comercios pequeños afecta directamente a su demanda y esta situación los pone en posición desfavorable para la negociación con estas grandes empresas que tienden a convertirse en sus principales compradores e inclusive en sus únicos compradores.

De esta forma, estos grandes compradores terminan ejerciendo un poder monopólico sobre sus proveedores, esto les permite que, con cada apertura de un hipermercado al que abastece un proveedor, a este se le debita un 5\% de la factura, con el argumento de que los proveedores también expanden su negocio, y en caso de remodelación edilicia del hipermercado, el débito forzoso es del 3\%. En otros casos, exigen descuentos anuales en el precio de lista que oscilan entre el 10\% y el 30\%. Estiran los plazos de pago de 30 a 60 días. Débitos por "ahorro logístico" que consiste en cobrarle a los proveedores lo que se ahorran en fletes, dado que los hipermercados instalan centros de logística en los cuales los proveedores dejan la mercadería evitando transportarla hasta cada centro de ventas, ya que son los mismos hipermercados los que distribuyen la mercadería entre sus locales. También cobran la ubicación en las góndolas al precio de un camión de mercaderías gratis por cada local. ${ }^{37}$

La competencia entre estos grandes emprendimientos, que parece haberse instalado en los mercados, hace que estos recurran a estrategias que afectan la rentabilidad de sectores históricamente competitivos del mercado argentino, como es el caso de el azúcar, que era ofrecida en el hipermercado Wal Mart a un precio menor al de su costo presionando la baja del precio artificialmente, ${ }^{38}$ porque, para quienes comercializan este producto, les resulta más conveniente comprarlo en el hipermercado que directamente a los productores, ya que les permite vender más barato sin reducir su margen de ganancia. ${ }^{39}$ En esta misma línea, una de las dos embotelladoras más grandes de Argentina redujo un 6\% su facturación a causa de la baja en el volumen vendido de la marca "Pepsi" (principal demandante de sus servicios) como consecuencia de que los hipermercados comercializan bebidas cola de su propia marca a un precio bajo. ${ }^{40}$

Esto explica las distintas reacciones y argumentos que provoca el avance de estos emprendimientos a través de la red urbana. En el interior del país son muchos los pedidos de una ley u ordenanza que tienda a moderar el impacto tanto económico como urbanístico: En Rosario, el Partido del Progreso Social solicitó al Secretario de Planeamiento de la municipalidad una copia del anteproyecto por el que se resolvió como viable la instalación de un hipermercado Coto en los terrenos de la Yerbatera Martin con el argumento de que esta área es de un predominante uso residencial y no tiene prevista la instalación de un hipermercado. ${ }^{41}$ En Formosa, bajo la denominación de Ley de Habilitación de Grandes Superficies Comerciales, se pretende que la legislatura sancione una norma legal que limite la apertura de los supermercados en esa provincia y que limite sus horarios de apertura permitiéndoles abrir sólo un domingo cada dos meses. El argumento fundamental de esta norma es intentar frenar el esperado incremento de la desocupación que traería aparejado la apertura de hipermercados, en base al cálculo de que 100 almacenes dan más empleo que un hipermercado, y para proteger a los proveedores entre otras cosas porque los hipermercados pagan a los 90 días. ${ }^{42}$

En Neuquen, los empleados de comercio pidieron a los diputados de esta provincia que se adopte una legislación destinada a limitar la instalación de los hipermercados, basándose en un análisis que dice que los hipermercados captan entre 12 y 13 millones de dólares por mes de los 30 millones que forman parte del circulante por sueldos de la administración pública. ${ }^{43}$ En Santa Fe, hay presentado un proyecto de declaración para
37 Clarín, p.22, 13 de abril de 1998.

38 Es importante tener en cuenta que la baja artificial del precio, es decir, que los precios bajen no por aumento de la eficiencia o por reducción de costos, obliga a los productores a reducir costos para mantener precios competitivos, y esto puede afectar al salario de quienes trabajan en esta producción.

39 La Gaceta, Tucumán, 28 de marzo de 1998.

40 Clarín, p.24, 2 de marzo de 1998.

41 La Capital, Rosario, 14 de febrero de 1998.

42 El Comercial, Formosa, 14 de febrero de 1998.

43 La Mañana del Sur, Neuquen, 18 de febrero de 1998. 
44 La Capital, Rosario, 20 de Febrero de 1998.

45 Unos, Mendoza, 2 de marzo de 1998.

46 El Diario, Paraná, 3 de marzo de 1998.

47 Así lo manifestó Alfredo Francolini, presidente del Centro Comercial de Concordia. (El Argentino, Gualeguaychu, 2 de marzo de 1998).

\begin{abstract}
48 Verificaciones realizadas por la gobernación de la provincia de Buenos Aires en las localidades de San Martín y Quilmes, revelan que se produjeron 10.000 despidos por el cierre de comercios minoristas, con perspectivas a que se produzcan 8.000 más en el corriente año. Lo grave de la situación en esta provincia reside en que, en un lapso de 5 años, se habilitaron 160 hipermercados. (La Capital, Rosario, 22 de febrero de 1998).
\end{abstract}

49 El Diario, Paraná, 18 de febrero de 1998.

\section{¿Q U É D E B E}

que se suspenda la instalación de supermercados hasta tanto no se sancione una ley provincial sobre esta problemática. ${ }^{44}$ En Mendoza, la regional de APYME (Asociación de Pequeños y Medianos Empresarios) de San Rafael emitió un documento en el que apoya el proyecto de regulación de supermercados, hipermercados y grandes centros comerciales, para evitar el deterioro de la economía y el cierre de pequeños y medianos comercios. $^{45}$ En Concordia, la Asociación Coordinadora de Actividades Mercantiles de Entre Ríos y la liga de Almaceneros, Autoservicios, Distribuidores y Afines de Entre Ríos, hicieron petitorios ante la Cámara de Diputados de la Provincia para que se trate la ley sobre la instalación de hipermercados. ${ }^{46}$ En esta misma ciudad, la instalación de un hipermercado Norte provocó que se agotara el efectivo que había en plaza, como consecuencia de esto, no sólo la gente dejó de comprar en los comercios pequeños, sino que, además, no tienen como pagar las deudas contraidas con los pequeños comerciantes, esto provocó que estos comerciantes no puedan afrontar sus pagos tributarios y sus deudas con los proveedores. ${ }^{47}$

Si bien todos estos pedidos son válidos en su intención de no permitir que se monopolicen los mercados locales con sus sabidas consecuencias, están dejando de lado aspectos importantes de la vida urbana que son también afectados por la instalación de estos hipermercados. La mayoría de los proyectos de ley u ordenanzas tienden a regular a los hipermercados en cuanto al metraje cuadrado dispuesto para la venta o en cuanto al horario de apertura, pero no encaran los problemas derivados de las políticas de empleo o de qué manera compensar las consecuencias negativas que debe soportar la economía local por su establecimiento.

Si analizamos esto desde un punto de vista más dinámico, el resultado, a igualdad de otras condiciones, es que, en términos generales, la economía local se empobrece, esto provoca que la demanda en general se reduzca, tanto para los grandes comercios como para los pequeños y, por ende, para los proveedores, lo que conduce a nuevos ajustes incrementando el desempleo ${ }^{48}$ y nuevamente reduciendo el nivel de ingreso de la economía local y así sucesivamente hasta convertirse en un círculo vicioso que tiende al empobrecimiento general de la economía local. A esto contribuye adicionalmente el hecho de que las ganancias de los hipermercados tienden a salir de la zona, a diferencia de la de los pequeños comercios que contribuye a la demanda local.

En el corto plazo, este proceso se disimula porque la magnitud de las inversiones que realizan estos emprendimientos se presentan como una importante inyección de capital para las economías locales (y podríamos generalizarlo para la economía nacional), y es cuando lo analizamos en el largo plazo (o inclusive en el mediano plazo) que este análisis tiene más sentido. La reacción de los productores locales obliga a una empresa como Wall Mart a afirmar que el $90 \%$ de sus productos son de procedencia argentina y de las ciudades cercanas a sus filiales, ${ }^{49}$ pero nada dicen de las condiciones que imponen a estos proveedores.

\section{¿QUÉ HACER?}

Si se decide admitir la entrada futura de estas inversiones, pero limitando sus efectos negativos, es imperioso no sólo evaluar su impacto sino proponer medidas contrarrestantes eficaces.

Los resultados de tal evaluación y diseño de medidas dependerán del contexto de cada país. En una coyuntura de depresión de la demanda por trabajadores productivos y de 
escasez de oportunidades productivas para un sector de PYMES sin competitividad ni apoyo estatal, la ponderación del impacto de cierres y desempleo adicional que genera este proceso de concentración debería ser más alta que en un contexto de crecimiento con amplias oportunidades de reconversión del comercio tradicional a actividades productivas. Al momento de evaluar la eficiencia relativa del sector tradicional y el concentrado, es necesario tener presente que el mismo desempleo y subempleo resultantes de la desindustrialización, la reconversión y la reducción del sector público contribuyeron a sobredimensionar el sector de comercio cuentapropista, incluso unipersonal $(57 \%$ de establecimientos comerciales son de ese tamaño en Argentina). ${ }^{50}$ En ese sentido, es difícil ver como mera modernización del sector el proceso actual de destrucción de comercios. En Argentina hay aún 11.5 comercios cada 1.000 habitantes, mientras que ese número es menor en los países centrales donde ya se estabilizó la transformación del sector: Alemania (1.9), Francia (1.2), Italia (3.7) y España (4.9). Esto contribuye a reducir su competitividad y explica su poca resistencia económica ante la entrada de los grandes, pero no puede ser visto como mera ineficiencia sectorial, pues su estructura actual fue también una respuesta social a los problemas de desempleo estructural que el mercado no logró ni logrará resolver.

Esto se vincula asimismo con el proyecto socio-político: si prima una visión de sociedad integrada, con una relativa difusión de la propiedad privada entre miembros de una clase media importante, este proceso concentrador contribuye a destruir esa posibilidad y la posibilidad concomitante de construir alianzas sociales amplias para sustentar un programa democrático de gobierno local. Es útil tener en cuenta el ejemplo de Italia, que limitó fuertemente este tipo de grandes emprendimientos y apostó a la persistencia del pequeño comercio.

La respuesta no puede ser sólo pública. El pequeño comercio individual puede adoptar como respuesta una táctica de parecerse al gran competidor, ante la reducción del mercado y la renovada competencia entre los chicos por los intersticios de mercado microlocal. Esto incluye acciones como:

- extender horarios de atención a fines de semana

- dar servicio a domicilio

- aumentar la eficiencia del inventario, rediseñar los usos del espacio, mejorar la exhibición de productos, etc.

- reducir los márgenes de ganancia

- competir por la calidad de los productos ofrecidos

- competir mediante la atención personalizada

- diferenciarse incorporando marcas y rubros que no interesan a los grandes

- especializarse o diversificarse, según el mercado local tratando de segmentar el mercado $^{51}$

Una alternativa es agregar a esto formas de competencia cooperativa que busquen otros equilibrios con los intereses de los consumidores, impulsando con el apoyo del sector público programas basados en la organización solidaria: clubes de compra para bajar costos, redes de crédito (tarjetas locales), marcas paraguas propias, ${ }^{52}$ contratar asesoramiento profesional y otros servicios de manera conjunta (fumigación, flete, propaganda institucional) o de seguros (médicos o de riesgo), implementar proyectos de reforma urbana conformando distritos comerciales abiertos, etc.

En cuanto al impacto socioeconómico sobre el orden urbano, en particular sobre las reglas de sociabilidad expresadas en la organización del territorio, su evaluación variará con el proyecto social y político desde el cual se evaluar. Si se consideran deseables formas
50 Clarín, p.17, 4 de julio de 1997.

51 Clarín, Suplemento de Economia, 6 de octubre de 1997.

52 Clarín, p.20, 23 de febrero de 1998. 
de gobierno efectivamente democráticas y participativas así como una ciudad más equitativa y abierta, donde el encuentro socialmente plural en los espacios públicos de acceso libre sea una norma deseada, el impacto de los grandes emprendimientos puede ser considerado como regresivo, por su contribución directa e indirecta a la segregación socioespacial (esto debe ser evaluado teniendo en cuenta el carácter realmente semi cerrado de los espacios aparentemente abiertos). Tampoco es marginal pensar cual será el alcance democrático de una planificación concertada cuando en la mesa de negociación predominen los grandes monopolios antes que una rica diversidad de actores económicos pertenecientes al campo popular.

Ante el ingreso de estos emprendimientos en una ciudad, habida cuenta de los efectos negativos no deseados, la sociedad y su gobierno pueden decidir aceptar esas inversiones pero poniendo condiciones para minimizar su impacto urbanístico negativo: exigiendo que financien obras de vialidad, drenaje, pasos bajo vía, semaforización, mantenimiento de áreas verdes, o que contribuyan a la construcción de escuelas, traslado de villas en condiciones de riesgo, incluso agregando la contribución a fondos de compensación social. Sin embargo, es importante tener presente que si esas obras son realizadas directamente por la empresa, esto le da un halo filantrópico a lo que no es más que un conjunto de obras necesarias para hacer funcionar el complejo comercial en condiciones óptimas. Se les puede alternativamente exigir la contribución al gobierno local para que realice esas obras e incluso exigir una sobretasa municipal por impactos negativos no contrarrestables por obras públicas.

En el caso particular de Porto Alegre, en caso de negociar la entrada de nuevos monopolios, parecería que debe ser el gobierno, junto con los representantes del conjunto de la sociedad local en el Orçamento Participativo, quien negocie y decida las obras y otras medidas compensatorias a ejecutar, evitando una negociación particularizada entre las Asambleas zonales y las empresas, pues su impacto no es meramente urbanístico ni localizado en la zona inmediata, sino que tiene efectos urbanísticos en otras zonas afectadas por la competencia y en general alcances socioeconómicos para toda la ciudad.

Por lo demás, lo más importante no es compensar los costos sociales iniciales de la instalación, sino lograr establecer un marco de regulación para su funcionamiento futuro, atribución que posiblemente debe involucrar poderes jurisdiccionales no locales. Se podría tratar, por ejemplo, de asegurar que se van a mantener los precios bajos, pero no reduciéndolos por debajo de los costos, que no se va a reducir el personal, que se va a reentrenar personal desplazado cuando corresponda, que se van reducir horarios para equipararlos a los del comercio tradicional, que se van a someter a reglas de equidad o progresividad fiscal, que se van a imponer fuertes multas ante transgresiones a las leyes de comercio vigentes, que se va a limitar la repatriación de las ganancias o al menos asegurar una reinversión de parte de ellas en otras actividades en la zona, etc.

El poder de presión y negociación de estos capitales no es menor en un contexto dominado por las políticas neoliberales. Pero no es comparable al de las grandes inversiones productivas de bienes y servicios para la exportación desde la ciudad a otras regiones o países. Estos emprendimientos están interesados y necesitan localizarse en la zona (por lo que sería absurdo caer en guerras intermunicipales de exención impositiva para atraerlos, algo a lo que puede conducir la falta de cooperación entre municipios vecinos en zonas metropolitanas) y eso debe ser tenido en cuenta en las negociaciones.

Una amplia alianza popular y local es necesaria para sostener decisiones que pongan límites a los proyectos del capital comercial monopólico para captar los mercados locales 
y reorganizar los sistemas de abastecimiento y producción de bienes de consumo masivo. En esto hay que tener en cuenta también la tendencia de los grandes emprendimientos a convocar a cadenas exitosas de comercio local a asociarse con ellos en los centros concentrados que construyen, generando una división de intereses en el seno de las clases comerciantes autóctonas.

El interés del capital comercial por el mercado local potencia la capacidad de negociación local, pero como vimos puede ser demasiado disruptivo del orden social urbano. Si se llega a la conclusión de que el efecto de la entrada de estos emprendimientos es nocivo, se puede declarar a la ciudad libre de hipermercados, tal como lo han hecho algunas ciudades de Estados Unidos o el conjunto de Italia. Pero lo fundamental aquí será ofrecer alternativas de reestructuración eficiente y socialmente superiores del sector comercial. Si meramente se quiere mantener protegido al comercio tradicional, o bien proteger a las grandes cadenas ya existentes, se entregará un mercado cautivo a un comercio ineficiente y sin dinamismo si es que no monopólico él mismo.

Entonces, si se optara por limitar la entrada de las grandes cadenas de comercialización, esto debería ir acompañado del desarrollo de centros comerciales abiertos, donde se combinen de otra manera los factores que atraen a los consumidores a los centros cerrados: seguridad, mezcla de rubros y actividades culturales, buenos precios, agregando atención personalizada, productos garantizados, líneas de crédito de fácil acceso, horarios adecuados a las necesidades de los usuarios, etc. y, por supuesto, de una campaña de información completa (sobre efectos directos e indirectos de la inversión rechazada) a la población, que le permita participar activamente en el acompañamiento de tales alternativas.

En todo caso, es fundamental someter todas las grandes inversiones y proyectos de reforma urbana - productivas, comerciales o residenciales - al encuadre del Plan Director de la ciudad, que supuestamente expresa el proyecto de sociedad y economía local y pone restricciones a la estructuración del espacio urbano.

En la actual contradicción entre la centralización del poder económico a nivel global y la descentralización del poder político a nivel local, son las sociedades y poderes locales las que han sido encargadas de vigilar por la calidad de vida de la ciudadanía, y en ello es instrumental un Plan Director que vaya más allá del mero ordenamiento espacial. Sin embargo, ante las tendencias a la desindustrialización y exclusión imperantes, un Plan Director es insuficiente para encarar la tarea y se hace prioritario elaborar un plan integral de desarrollo social y económico local con un amplio consenso de las fuerzas sociales, económicas y políticas locales.

A B S T R A C T Following the request of Carrefour to expand its activities in Porto Alegre, a discussion is held concerning what local government should do. This article attempts to bring the Argentinian experience to bear regarding the strategies and consequences of global retail monopolies, and presents some policy alternatives.

K E Y W O R D S Commercial capital; commercial enterprise; economic impact; popular alliances.

\author{
José Luis Coraggio, eco- \\ nomista, é economista e pro- \\ fessor titular e pesquisador \\ do Instituto del Conurbano \\ de la Universidad Nacional \\ de General Sarmiento. \\ Ruben Cesar é aluno-moni- \\ tor do Instituto del Conurba- \\ no de la Universidad Nacio- \\ nal de General Sarmiento. \\ E-mail: \\ jlcoraggio@ciudad.com.ar
}

